\title{
Metaphors and analogies through smart materials to mitigate age-related differences in the understanding of technology
}

\author{
Massimo Micocci* \\ Department of Design, \\ College of Engineering, Design and Physical Sciences, \\ Brunel University London, \\ Kingston Ln, Uxbridge UB8 3PH, London, UK \\ and \\ Department of Surgery and Cancer, \\ Imperial College London, \\ St Mary's Campus, QEQM building, \\ Praed Street, London W2 1PE, UK \\ Email:m.micocci@imperial.ac.uk \\ *Corresponding author
}

\section{Gabriella Spinelli}

Department of Design,

College of Engineering, Design and Physical Sciences,

Brunel University London,

Kingston Ln, Uxbridge UB8 3PH, London, UK

Email: email: gabriella.spinelli@brunel.ac.uk

\begin{abstract}
Older adults, owing to their changing physical and cognitive abilities, might still be challenged by understanding and adopting smart technologies. In line with such research enquiry, 'metaphors' and 'analogies', powerful learning tools for written and verbal communication, have been investigated as 'non-linguistic' tools, when embedded into product shapes and features, to facilitate the users' understanding of products' functionalities. In this study, analogies and metaphors are physically 'embodied' into products' design through the adoption of smart materials (SMs). A novel device was designed to explore such approach using four different SMs families to evaluate which design would be more intuitive for two groups of users in a comparative, exploratory study. Findings reveal that embodied SMs help considerably in the mitigation of age-related differences and in the understanding of technologies due to facilitated retrieving of older adults' prior knowledge. This, in return, may increase the chance of technology adoption among ageing users.
\end{abstract}

Keywords: human-centred design; product design; analogical reasoning; technology; metaphors; smart materials.

Reference to this paper should be made as follows: Micocci, M. and Spinelli, G. (2018) 'Metaphors and analogies through smart materials to mitigate age-related differences in the understanding of technology', J. Design Research, Vol. 16, Nos. 3/4, pp.282-313. 


\begin{abstract}
Biographical notes: Massimo Micocci is a Research Associate in Human Factors at the NIHR London IVD Coop, Imperial College London. His areas of interest and contribution include inclusive design and human-centred technology development. In the past years he has investigated cognitive differences in the adoption of technological devices between younger and older generations and advanced strategies to design intuitive and immediate interactions for health and wellbeing products.
\end{abstract}

Gabriella Spinelli is a Reader in Design in the College on Engineering, Design and Physical Science at Brunel University London. She is interested in research that explores the relationship between, health and wellbeing, social circular economy and co-designed interventions. In the last ten years, her research interests have developed in the area of innovation and ageing as this is an unprecedented challenge that poses interesting societal questions and provides opportunity for social innovation and development.

This paper is a revised and expanded version of a paper entitled 'Actualising agency through smart products: smart materials and metaphors in support of the ageing population' presented at 6th STS Italia Conference - Sociotechnical Environments, 24-26 November 2016, Trento (IT).

\title{
1 Introduction
}

'Ageing' is often intended as a process of deficit accumulation and a decrease in physiological reserves that may reduce the adaptability to stressful and changing situations (Fulop et al., 2010). Age-related decrements occur when processing external stimuli-sensation and in the interpretation of information that results from sensation-perception (Fisk et al., 2009). Cognitive deficits brought on by the ageing process normally consist of difficulties in thinking, problem-solving, reasoning and decision-making. Reduction in working memory, defined as the "memory that has just been perceived and refers to the capability to keep information active while we work on it" [Fisk et al., (2009), p.19] is typically found in older adults along with a reduced ability to discern differences between items too similar; this is caused by the reduced ability of the hippocampus to encode contextual details used for discrimination (Elfman et al., 2008). Conversely, the long-term memory, referring to a permanent storage of knowledge (i.e., semantic memory: meaning of words and directions of 'on/off' switch button) does not decline with age.

Smart technologies, defined as "autonomous physical/digital objects augmented by sensing, processing, and network capabilities [...] in order to sense, log, and interpret what's occurring within themselves and the world, act on their own, intercommunicate with each other, and exchange information with people" [Kortuem et al., (2010), p.44], are advanced technology that could support older adults to compensate for declining cognitive skills. Although older adults appear keener to adopt technologies in support of their safety at home and for the promotion of their personal wellness and health (Mitzner et al., 2010), their adoption rate is still rather low. Smart technologies mainly rely on internet platforms and are designed with the inbuilt assumption that the users would have internet access. This is of concern considering that just only the $54.4 \%$ of the population worldwide access to internet [dataset] (Internet World Stat, 2017). In the UK the Office 
for National Statistics reported that in 2017, 51.9\% of adults aged 75 years and over never used internet, in contrast with the $0.5 \%$ of people aged 16 to 24 years [dataset] (ONS, 2017). The different acquisition of digital technologies by older adults compared to younger generations is named 'digital divide' (Government Office for Science, (2015), p.4) and it is demonstrated to be affected by multiple reasons: lack of skills and confidence (Heart and Kalderon, 2013), social support (Hill et al., 2008), financial constraints (Lee and Coughlin, 2015), cognitive abilities and computer anxiety (Czaja et al., 2006), inadequate training and lack of ongoing support (Digital Inclusion Panel, 2004) and lack of perceived need/motivation (Melenhorst et al., 2006; Morris et al., 2007). It is sometimes suggested that the digital divide is a short-term phenomenon and that, as a growing number of computer literate people move into old age and due to initiatives specifically designed to encourage and teach older people to use computers, such divides will disappear (Government Office for Science, 2015). The perceived benefits derived from the adoption of digital products are the leading reason as to why older adults purchase and fully use a new technological product (Jensen, 2008; Mitzner et al., 2010). However, literature explains how the extended learning time required to familiarise with the technology, longer than that of younger users (Rogers et al., 1998), is a major factor affecting the acquisition of a novel technology. Specifically, studies conducted by Barnard et al. (2013) theorised the presence of a hump of 'max learning pain' on the curve that traces the task difficulty vs. the learning time. The engagement with technologies is therefore facilitated and encouraged by strategies that consider a minimisation of the perceived learning difficulties, in other words strategies that prevent the users to reach the max learning hump. Manufacturers are currently undertaking a trial-and-error strategy designing smart objects whose benefits are readily perceived by older adults so as to facilitate their understanding, reduce learning time and enhance overall usage. Examples of such attempts include product interfaces that compensate for the lack of older adults' sensorial perception and create pleasant and engaging interactions that maximise their cognitive and sensorial abilities (Fisk et al., 2009).

Scholars have identified solutions that reduce the learning load of new tasks and accommodate the changes that the ageing process involves. Gregor et al. (2002) adopted a methodology to determine the dynamic diversity of older adults for software development by adapting its functionality as function of the 'diversity' of the user; Naumann et al. (2010) attempted to demonstrate how the adoption of multimodal interfaces, considering touch, speech and motion control, may have benefits over the single modality interface of a mobile phone in terms of task completion and user satisfaction. Although this study demonstrated that multimodal condition was slightly better than the single modality option, the reluctance of older adults in trying new modalities of interaction and the cognitive overload occurring hinder the efficiency of the multimodal option. Growing attention has been paid to investigate the role of 'metaphors' in products design and interfaces to support an intuitive interaction with products. Leonardi et al. (2010) explored the user of real world 'metaphors' to design of interfaces that accommodate the cognitive needs of older adults, being able to activate patterns and emotions already experienced before and provoking a sense of anticipation that turns the interaction into something that is highly recognisable. Metaphors are alongside analogies adopted in verbal expressions to enhance the way information is communicated and understood; however, given their importance in the learning processes, studies are conducted to explore new applications of metaphors and their role in the design process (Neale and Carroll, 1997; Saffer, 2005; Özcan and Sonneveld, 2009; Johnson, 2013). 
Krippendorff and Butter (2007) explain how non-linguistic metaphors, those metaphors grounded in the domain of artefacts, shift practices and experiences from the context of familiar source domains to a less familiar target domains; the so established parallel between familiar/unfamiliar domains make situations that users struggle with more understandable. In a recent study, Cila $(2013$, p.5) developed the concept of product metaphor as: "any kind of product that is shaped to reference the physical properties (e.g., form, sound, movement, smell, and so on) of another distinct entity for particular expressive purposes". While in a verbal metaphor, the correspondence between domains occurs with words, in a product or interface the mapping occurs through tangible features or characteristics of the artefacts (Hey et al., 2008). Studies on tangible interactions demonstrate that the use of embodied metaphors on tangible artefacts promote learning in children (Bakker et al., 2012).

To date, further insights are needed to demonstrate the use of metaphors in product designs to reduce the learning gap between generations when interacting with smart technologies and how memories and sensorial experience may be retrieved to activate familiar cognitive patterns.

Opportunities are sought with the application of 'materials' whose dynamic properties are exploited to build a richer dialogue with the user (Spinelli et al., 2017); a new class of high-performance materials, defined as 'smart materials' (SMs), have been lately explored for the influence their features might have in the attribution of an intuitive and immediate meaning to the product in their application as product interfaces (Nijholt et al., 2012; Micocci et al., 2017). These materials have engineered changeable properties that can reversibly alter their shape or colour in response to physical and/or chemical influences, e.g., light, temperature or the application of an electric field (Ritter, 2007). Due to this dynamic behaviour, SMs are characterised by two or more appearances that challenge designers to find applications other than of conventional materials and to create ingenious ways to experience them.

In this paper, alongside a review on 'intuitive' interfaces, SMs are explored as a vehicle of sensorial stimuli and intuitive prompts that maximises older adults entrenched knowledge and cognitive abilities when interacting with a novel device. The so defined 'embodied SMs', are SMs embedded into product design with the purpose of conveying metaphors and analogies, which allows the user to retrieve stored knowledge and link it to novel information. The underlying hypothesis of the research presented here is that the sensory attributes of SMs may help to establish more intuitively the relationship between knowledge in the source domain and the target domain (e.g., a new product or interface) through tangible features; this unexplored application of SMs is expected to simplify the way a new product is understood and, therefore, more likely to be adopted by older adults.

\section{Retrieving stored knowledge of older adults: non-linguistic metaphors in product design}

Scholars have explained how the intuitive use of a product is attributable to the subconscious application of the users' stored knowledge (Mohs et al., 2006; Blackler and Hurtienne, 2007; Blackler et al., 2012). In a study conducted on older adults (Blackler et al., 2010), it was found that intuition is correlated to past experience with similar product's features and it is affected by age, assuming that older adults have limited 
exposure to novel technologies. This means that the more familiar a product is perceived as, the more likely older adults will intuitively use it (ibid). In another study, Blackler et al. (2012) found that the performance of older people when interacting with various interfaces is affected negatively by the decline in cognition and positively by familiarity with the product's features. In line with the above, Hurtienne et al. (2015) uncovered the dilemma on whether designers should pursue familiarity, as this enhances the prospects of adoption, or seek innovation through new products that break past moulds. The design of products that are simultaneously intuitive, innovative, and inclusive is, therefore, a challenge. The emerging factor that contributes to making a product more immediate for older adults are managing the transfer of the existing 'image schema' the user has of a product to a new device (Blackler and Hurtienne, 2007). The term image schema is used in cognitive linguistic literature (Lakoff and Johnson, 2008) to define dynamic structures arising from perception, bodily movements, manipulation of objects, and experience of force or simply "dynamic representations of spatial relations and movements in space" [Gibbs and Colston, (1995), p.349). Up-down, centre-periphery, in-out, are image schemas developed from recurring ordinary interactions that the brain retains. By managing the transfer of the existing image schema, to the new device is a factor that contributes significantly to its intuitive use among older adults (Blackler and Hurtienne, 2007). Hurtienne et al. (2015) have identified seven macro-categories of image schema that are context dependent and do not have to literally mimic the familiar products' appearance to induce the transfer of entrenched knowledge. The resulting association of the image schema with a specific existing domain of information is what Grady (1997) called 'primary metaphors', lately called by Hurtienne et al. (2015) image-schematic metaphors.

Differences between metaphors and analogies lie in the way two different domains are related and the quality of new knowledge they permit to infer. An 'analogy' is a relational structure applied from one domain to another, e.g., "The X12 star system in the Andromeda galaxy is like our solar system", while 'metaphors' are predominantly relational comparison with a specific focus on the attributes they match, e.g., "She is a giraffe," used to convey that she is tall (Gentner, 1983). The crucial aspect of metaphorical language is the transfer of information from a source domain (familiar) to a target domain (unfamiliar area or situation) enabling people to use specific prior knowledge to understand novel or unfamiliar ones (Neale and Carroll, 1997). While an analogy explicitly compares the structures of two domains, a metaphor compares them implicitly, unveiling relational qualities that do not literally coincide in the two domains. Essentially, metaphors always evoke a 'surprise effect' and a cognitive 'anomaly', being the grounds of the comparison hidden. In this way, the basis of comparison is revealed or created by the addressee of the metaphor (Duit, 1991). In other words, a metaphor entails an implied comparison with something else, while analogies work as an 'illustration' of an idea through another familiar one (Hey et al., 2008); therefore, as metaphors are implicit, the cognitive effort in their interpretation is greater.

In a traditional view of learning, the learning process is viewed as a conceptual growth (Gagne, 1970 in Duit, 1991) while in a constructivist view of learning, as explained by Duit (1991), learning is often not just a continuous chain of augmentation but a radically new construction of the already known. Analogies come into play within this view, generating new schemas by transferring structures from source domains to target domains and helping to restructure existing memory and to prepare it for new information. Metaphors work in a different way, they are significant for the 
aforementioned 'surprise' or 'anomaly' aspect they generate. As explained by Gowin (1983 in Duit 1991) when we encounter a new metaphor, we reorganise our pattern of previously organised meanings and we see what was already familiar in totally new ways. Metaphors are one possible way of producing an anomaly and, hence, inciting a cognitive conflict with what is already known that stimulate the reader's reasoning and restructure a novel pattern of meanings (Duit, 1991). Although the perception of experience by human beings occurs as a continuous flow, it is actually fragmented and it is expressed and understood through the mediation of language (Tsoukas, 1991); language is, therefore, both descriptive and constitutive of reality: while literal utterances describe the world where the sentence meaning coincide with the utterance meaning, metaphors and analogies help constitute and evaluate that reality. Metaphors are, by definition, partial in their representation of reality as they must emphasise certain features at the expenses of others, being a representation of a continuous flow of experience (Tsoukas, 1991). Metaphors are also of importance for the degree of imagination they provide, which helps to visualise abstract ideas, the ability to link thinking with feelings and to bridge the gap between the cognitive and affective domains of learning (Duit, 1991).

The process of association between two domains of information begins with a person learning new information that becomes entrenched knowledge. This at some point is recognised as useful and retrieved (Hey et al., 2008). Retrieving entrenched knowledge structures is the most cognitively difficult step but once a knowledge source is identified, a mapping can be created between the source and the new target domain. Beer (1966 in Tsoukas, 1991) explains how elements of a given domain can correspond in various ways to elements of a second domain: a one-to-one correspondence between domains is called isomorphism (e.g., a map and the town it represents) while a many-to-one transformation is called homomorphism where only important structural information are preserved (e.g., a homomorphic model of an atom can be developed in comparison to the solar system by dropping the unnecessary properties of the sun, such as its yellow colour while preserving higher order relationship such as "the sun's attraction of the planet causes them to revolve around it" - Gentner, 1983). The contribution of metaphors to learning can be summarised with the words of Gentner (1989, p.201): "it is preferable to map connected systems of relations governed by higher order relations with inferential import, rather than isolated predicates."

Figure 1 Physical mapping between the source domain and the target domain (see online version for colours)

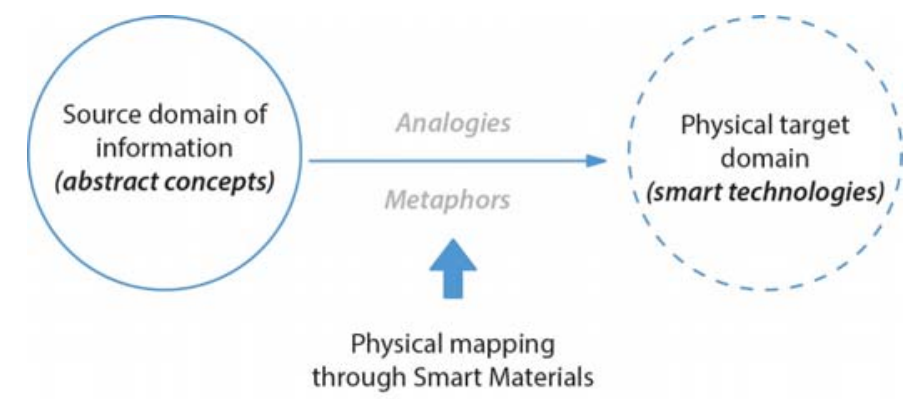

Source: Adapted model from Hey (2008) 
In light of the theory of metaphor generation, the embodiment of SMs is expected to simplify the generation of high order relations between attributes of two domains making more accessible, at the product interface level, the desired information. Therefore, the application of SMs acts as a physical conveyance of the knowledge mapping that occurs in metaphor (Figure 1) and their embodiment would then be supposed to minimise the negative effect caused by the lack of prior exposure and familiarisation to technologies among older adults making the acquisition of new information more intuitive.

\section{Research design: the smart radio study}

The adopted methodological framework reflects a qualitative inductive approach. However, for the sake of consistency in data collection, a questionnaire was used.

With the premise that older adults find less intimidating devices they had prior exposure to (Blackler et al., 2010), a 'radio' appeared to be a product whose components, commands and functions could be more familiar to the target users so that they could focus on the proposed interactions.

Figure 2 The prototype of the smart radio used in the study (see online version for colours)

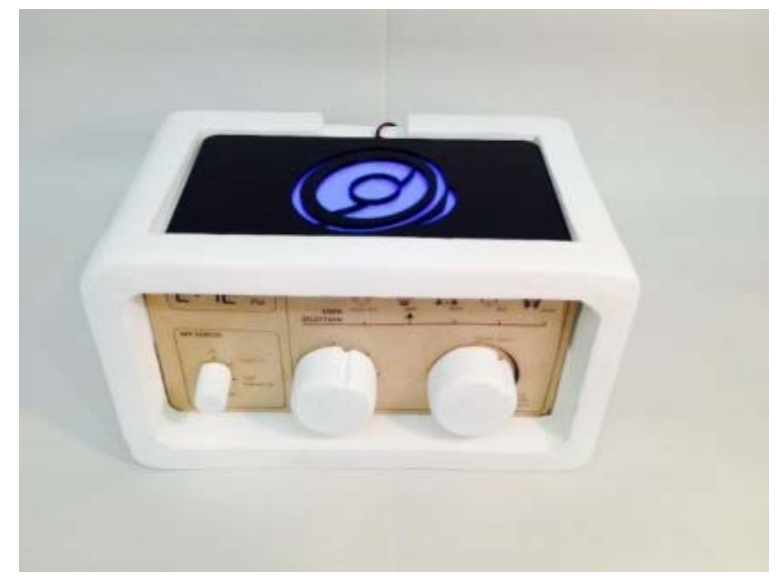

A smart radio (Figure 2) was specifically designed to keep the aesthetics of a conventional radio and, instead of broadcasting music, the device was presented as a technological product able to connect users wirelessly with the following functionalities:

- browsing and connecting to four different pre-set contacts, i.e., friends and relatives, (instead of radio stations)

- exchanging information with the selected contact enhancing the communication between peers through non-intrusive details of the activities parties are engaged with.

Figure 3 shows the smart radio interface. 
Figure 3 Display of the smart radio in the default modality with the three knobs indicating: (on the left) the status of the device, (central knob) the contacts browsing and (on the right) the amount/nature of information to be acquired

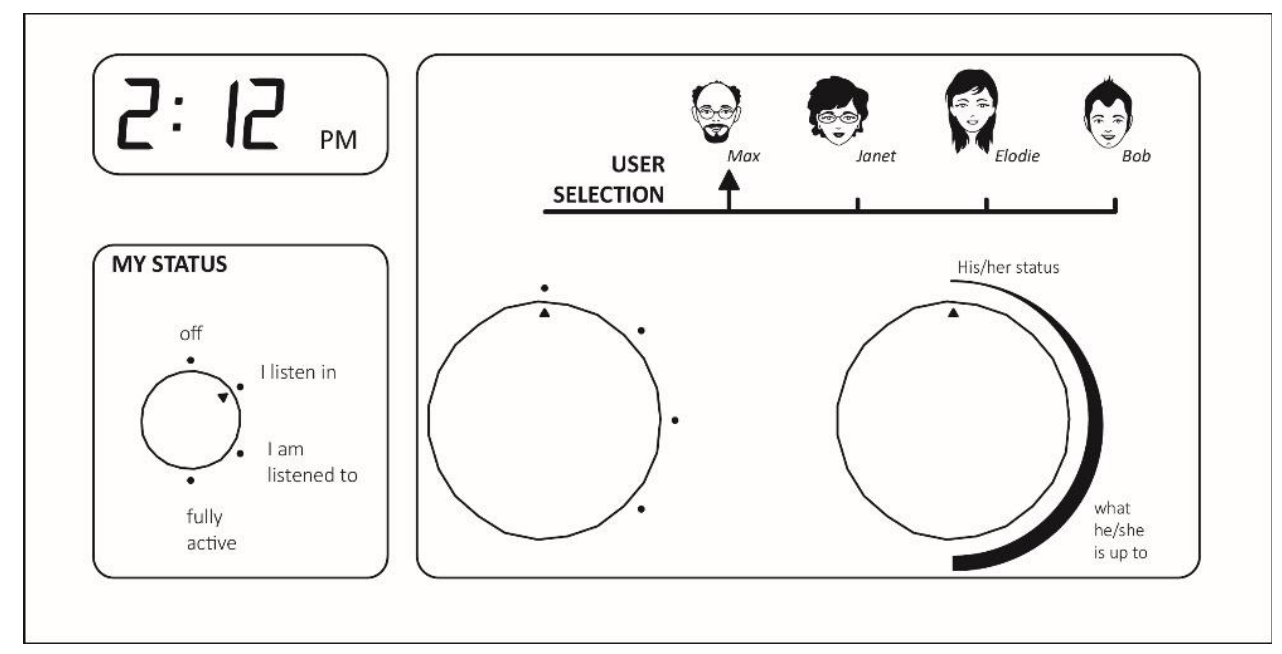

Embodied analogical and metaphorical messages were displayed on the radio top surface. Messages were conveyed by four families of SMs, considered as representative of the potential dynamic sensory attributes that SMs have:

1 Light emitting materials: energy-exchanging materials that produce light when their molecules are excited by the effect of energy, e.g., the effects of light or an electrical field (Ritter, 2007).

2 Shape changing materials: property-changing SMs that are able to reversibly change their shape and/or dimensions in response to one or more stimuli (Ritter, 2007).

3 Rheological changing materials: rheological fluids are those liquids whose viscosity properties can be modified by an external stimulus (Lozada et al., 2010). This stimulus can be a magnetic or electric field and, in both cases, the external field acts on the micron-sized particles in suspension into the carrier fluid.

4 Changing colour materials: technically called chromogenic SMs, are materials in which a change in an external stimulus (such as light, temperature or chemical environment) produces a change of the absorption of reflectance of its optical properties (Papaefthimiou, 2010).

Each group of SMs was used in eight signals, of which four encoded analogical and four metaphorical messages. Analogical messages were selected to communicate the 'availability of the user', e.g., the status of availability of each contact. These were represented by the dynamic on/off alternation of two symbols by means of 'ear' and 'lips' appearing on the surface of the smart radio: 
- offline: the connected device is offline, the contact is offline (ear and lips symbols are off)

- the contact is listening in: the connected device is receiving information (only ear symbol is on)

- the contact can be listened to: the connected user/device is sending information (only the lips symbol is on)

- fully active: the connected user/device is both sending and receiving information (ear and lips symbols are on).

The four families of SMs have been applied to communicate slightly differently the appearance of the ear and lips symbols in the following way:

a alternating lighting symbols (light emitting materials)

b movable flaps revealing underneath ear and lips (shape changing materials)

c popping up and tangible symbols (rheological changing materials)

d appearing symbols with a traffic light colour coding scheme (changing colour materials).

Metaphorical messages were used to communicate the intensity of activity the connected user was involved with, namely:

- the connected user is highly stimulated (e.g., doing exercises)

- the connected user is stimulated but quiet (e.g., housekeeping, gardening, cooking)

- the connected user is active but relaxed (e.g., eating, watching television, reading a book)

- the connected user is highly relaxed (e.g., sleeping).

The level of intensity of the user activity was conveyed again through the application of the four SMs families as described below:

a with light emitting materials, the alternation of blinking and pulsing light communicated whether the user was engaged in highly stimulated or highly relaxed activity;

b with shape changing materials, sharp vs. smooth shapes, fast vs. slow pace shape movements conveyed the intensity of the user activity

c with rheological changing materials, the size and the spatial gaps in bubbling set of shapes communicated the intensity of activity;

d with changing colour materials, primary vs. secondary colours and colour contrast were used to convey the different activities.

Figure 4 depicts the interaction between two users. 
Figure 4 Functionalities of a set of smart radios (see online version for colours)

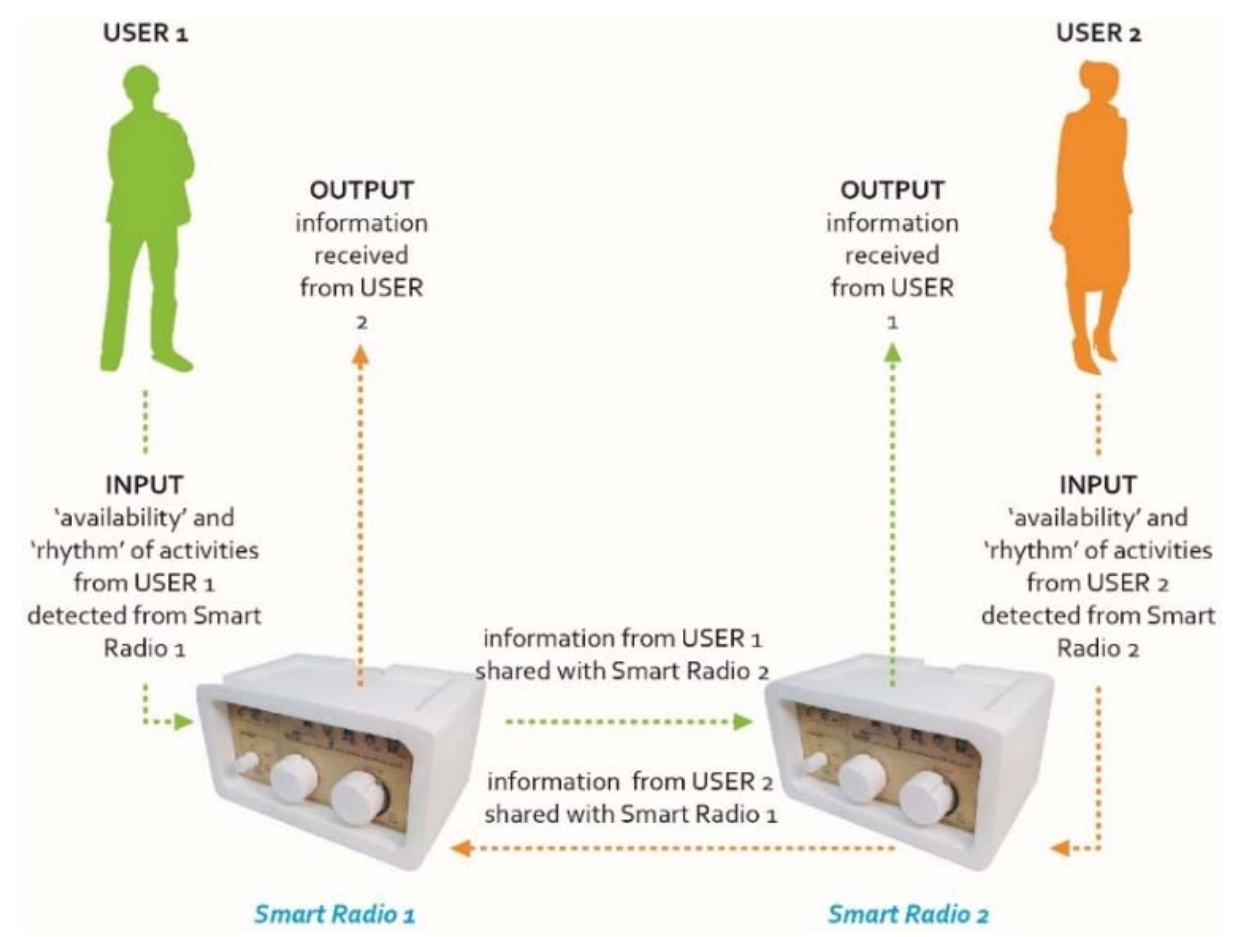

Notes: Each device detects information about the level of activity of the user using it and it broadcasts that information to another connected device/user who is listening in.

\subsection{Designing the smart radio}

An initial set of associations between 32 SMs' outputs and their potential meanings was created. Outputs were designed considering commonly used mappings of form/function (Hurtienne et al., 2015). This set of associations represented the 'designer mental model of the smart radio', the way the designer imagines the product to work and linked the signifiers (the signals encoded by SMs) with the signified (the hypothetical activity of the user connected). This was used as the benchmark to evaluate the responses of the participants. Tables 1-4 explains the 32 signals displayed and their associated meaning.

\subsection{The study protocol}

Each participant signed a formal consent where they accepted to perform the test and to share their personal data for research purposes. Participants' names were carefully replaced to protect their anonymity. A $£ 5$ Amazon voucher was given to each participant as a reward for their time and input. The study followed the protocol described below:

1 Technology familiarity (TF) questionnaire: a pre-test aimed at defining the level of familiarity with the product category of each participant. The TF questionnaire was structured considering the original version designed by Blackler et al. (2010) and adapted to radio related technologies. The TF questionnaire was a self-rating 
questionnaire asking participants how often they used certain technologies, and how much of the functionalities of those products they used. It was designed considering how often participants used a digital radio fully equipped, a standard portable digital radio, a radio embedded in other products (like in a smartphone) and a car radio. As conducted in the model of Blackler et al. (ibid.), prior exposure to conventional communication tools, such as smartphones, tablets, social networks, telecommunication applications (Skype, Twitter) and the personal computer was also probed. Participants were asked to estimate how often they used the listed products/technologies based on the following options: every day, several times a week, once or twice a week, every few weeks, every few months, only ever used it once or twice, never. In line with Blackler et al. (ibid.) users were also asked how many features of the listed products they commonly used and the alternatives available were:

a all the features

b as many features I can figure out without manual

c just enough features to get by

d my limited knowledge of the features limits my use of the product

e none of the features - I do not use the product.

In the TF questionnaire, more exposure to and knowledge of certain products specifically selected produced a higher TF score. The maximum possible score on this questionnaire was 100 while the minimum was 0 .

2 Interaction with the smart radio prototype and smart radio evaluation questionnaire, divided into four sections one for each family of SMs. The questionnaire helped understanding if and how age-related differences in the understanding of a smart radio are minimised when embodied SMs are adopted, and how a novel technology can be understood even for a subgroup with a limited prior exposure to technologies. In each section, participants were given the list of eight SMs' outputs (signifiers) and the list of their potential meanings (signified); they were asked to provide one association signifier/signified and to give a score (1 to 3 where 1 is the weakest association) based on the effectiveness and intuitiveness of the identified association. An option of 'others' was also available to participants when they could not attribute any of the suggested meanings to the presented signals. Three open questions at the end of the main questionnaire were included to let participants freely articulate their preferred signals and ways to improve the device. Participants were asked:

a which of the signifiers better represented the availability of the user

b the level of activity the connected user was engaged with

c how the digital radio should be improved.

After a detailed explanation of the study and after the TF questionnaire was completed, participants were invited to use the smart radio and to browse the four hypothetically connected users one at a time and receive messages from them. As the prototype of the radio was not fully functioning, the participants could not operate the device in full. However, a realistic feel for the interaction and behaviour of the device was achieved through material demonstrators; rheological changing materials interactions were showed through a video for safety concerns. 
Table 1 Light emitting materials communicating the status of the device (analogical messages) and the nature of the activity the user is involved (metaphorical messages) (see online version for colours)

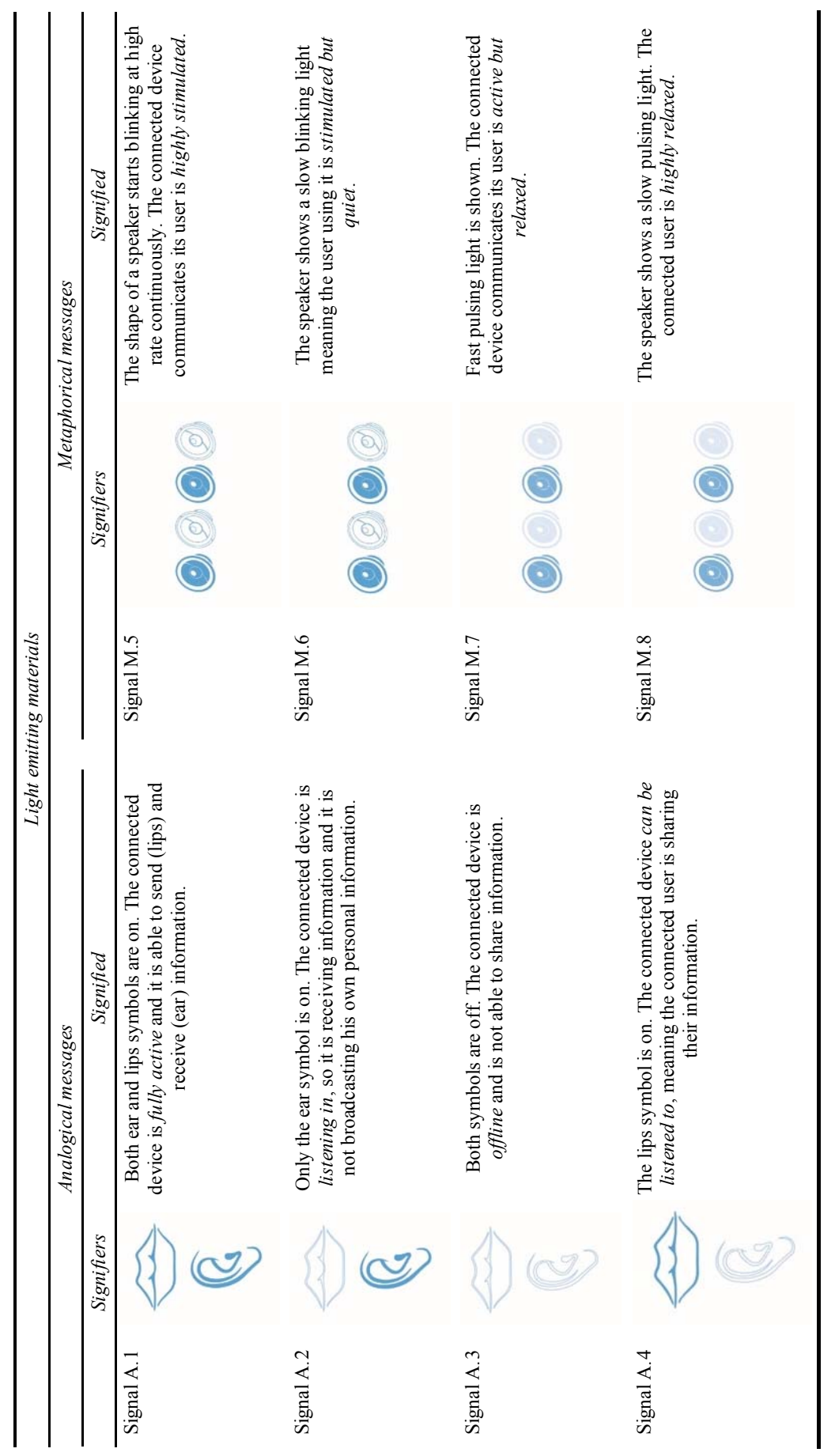


Table 2 Changing shape materials communicating the status of the device (analogical messages) and the nature of the activity the user are involved (metaphorical messages)

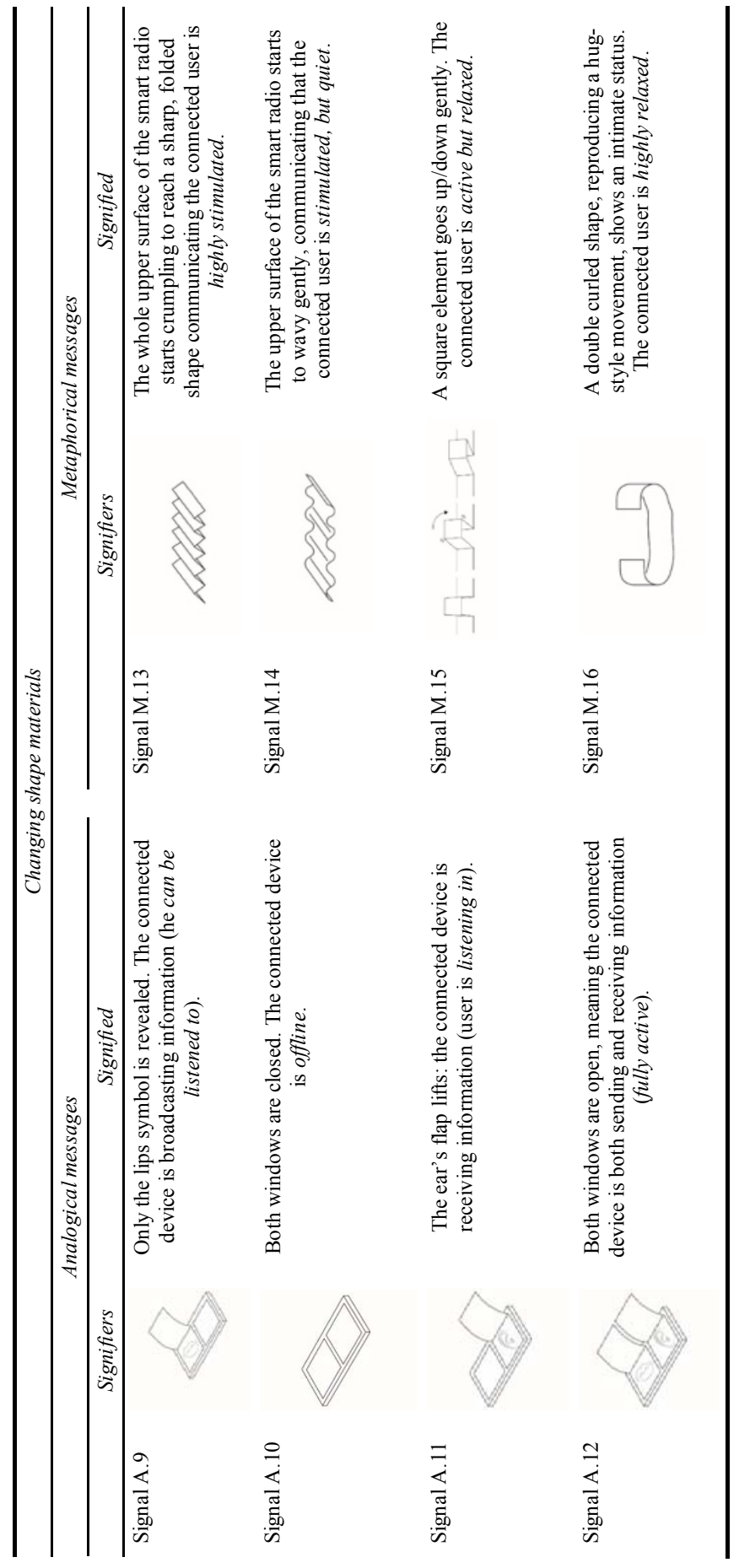


Table 3 Rheological changing materials communicating the status of the device (analogical messages) and the nature of the activity the user is involved (metaphorical messages)

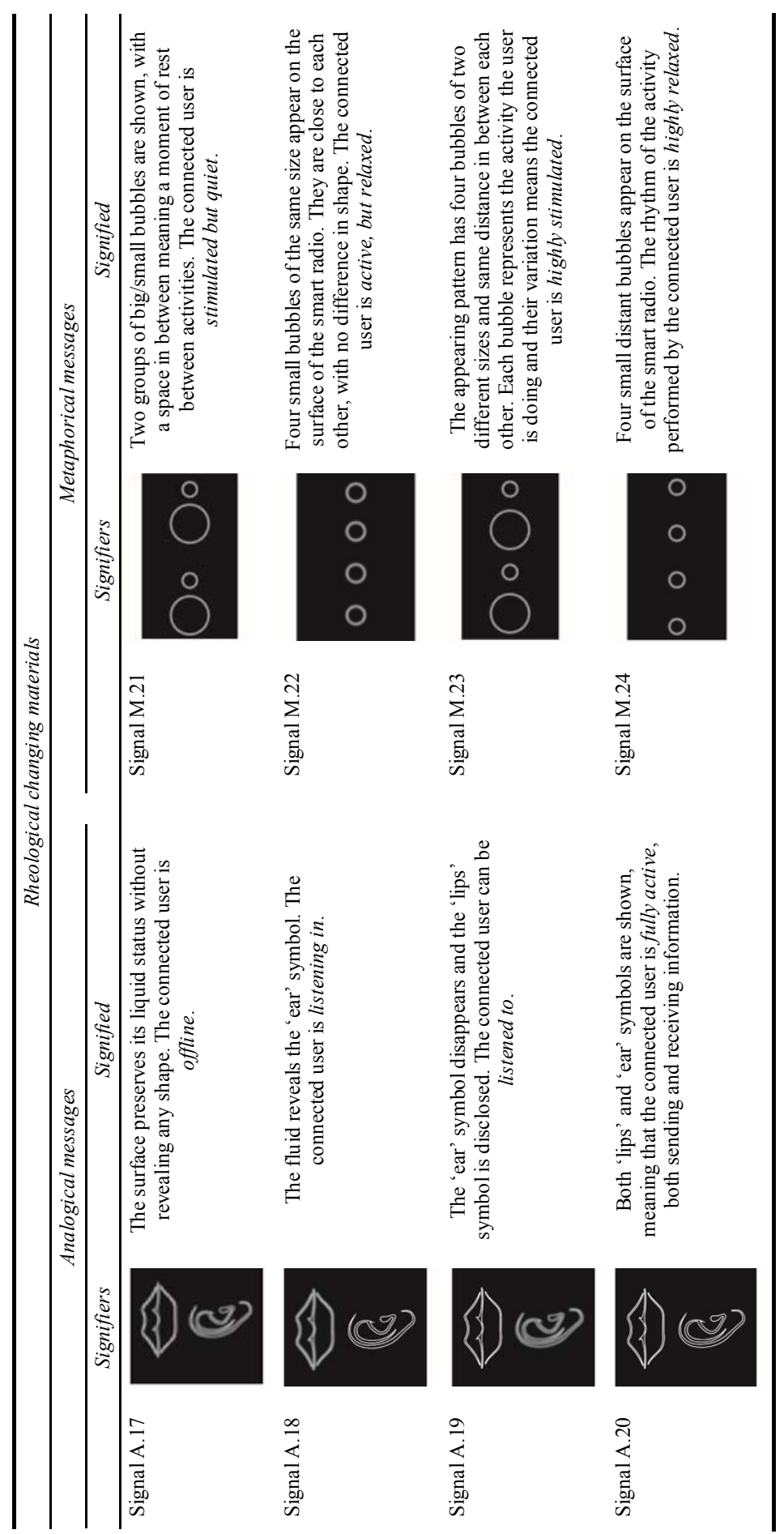


Table 4 Changing colour materials communicating the status of the device (analogical messages) and the nature of the activity the user is involved (metaphorical messages) (see online version for colours)

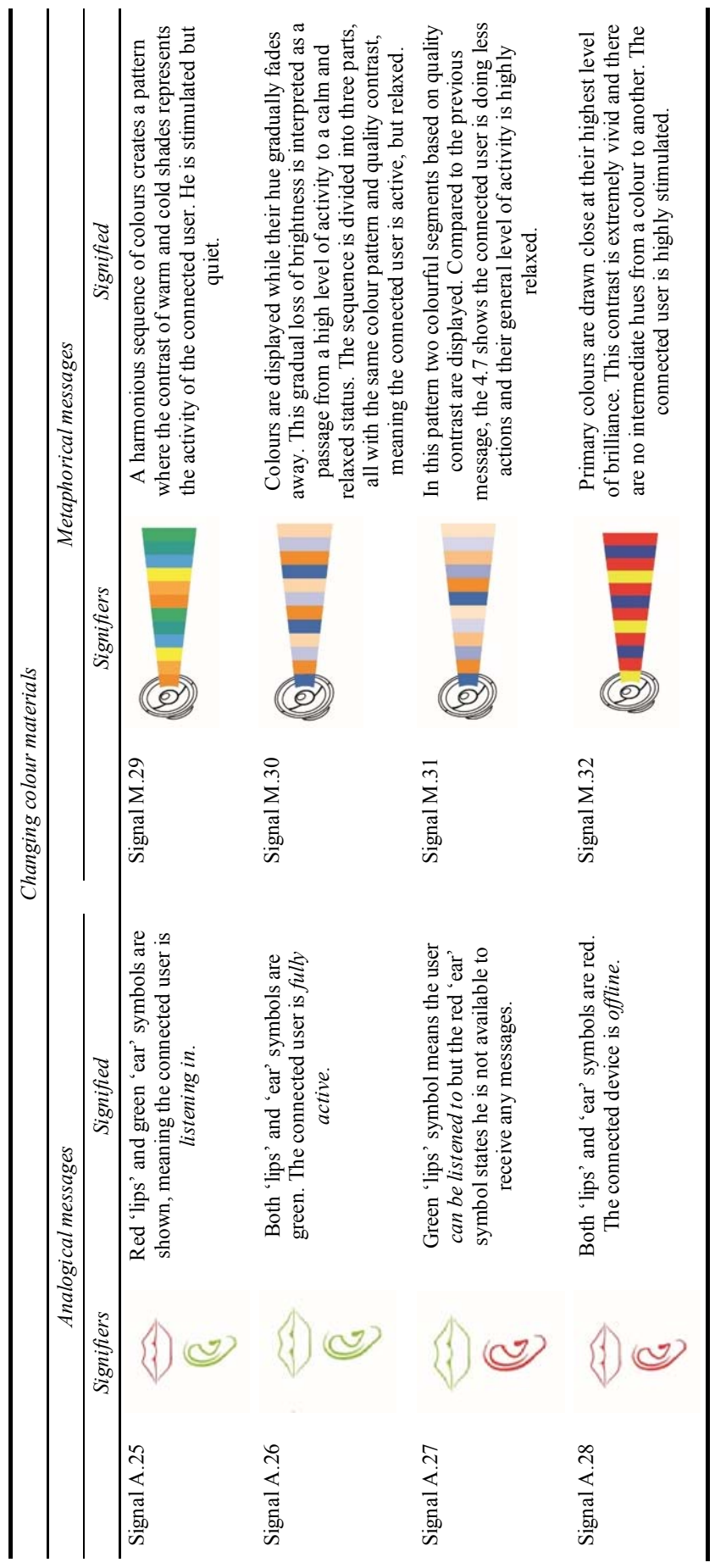




\subsection{Participants selection}

The smart radio evaluation applied a quasi-experiment procedure; the two subgroups selected differed only for age and general level of familiarity with the technology. Participants were conveniently selected to represent two distinct age groups: under-60 years old and over-60 years old people. Under-60-year-old participants were recruited from the local University in London, while the over-60-year-olds were selected through the $50+$ group of the same institution - a large panel of retired people meeting on a weekly basis to socialise and to practise sport: Age UK Hackney, a residential care facility in Uxbridge (London) and the Uxbridge Civic Library. This study included participants with no distinction of ethnicity, nationality, economic background, and physical condition but with a high motivation to provide their feedback for the assessment of a novel technological device. A total number of 62 participants (Table 5) took part in the main study (females $=40$, males $=22$,) whose age span from 21 to 84 years old (median age $=59.5$ ). They were distributed into two groups:

- Under-60 years old: $\mathrm{N}=31$, age span from 21 to 59 years old, mean age $=35.6$ years old; males $=14$, females $=17$;

- Over-60 years old: $\mathrm{N}=31$, age span from 60 to 84 years old, mean age $=71.5$ years old; male $=8$, female $=23$.

Table 5 List of participants of the study

\begin{tabular}{|c|c|c|c|c|c|c|c|}
\hline \multicolumn{4}{|c|}{ Under 60-year-old participants } & \multicolumn{4}{|c|}{ Over-60-year-old participants } \\
\hline $\begin{array}{l}\text { Fictional } \\
\text { name }\end{array}$ & Age & Gender & TF score & $\begin{array}{c}\text { Fictional } \\
\text { name }\end{array}$ & Age & Gender & TF score \\
\hline William & 21 & $\mathrm{M}$ & 51 & Sophia & 60 & $\mathrm{~F}$ & 51 \\
\hline Samantha & 24 & $\mathrm{~F}$ & 82 & Diana & 60 & $\mathrm{~F}$ & 45 \\
\hline Horacio & 24 & M & 70 & Sharon & 63 & $\mathrm{~F}$ & 7 \\
\hline Johnny & 25 & M & 70 & Rose & 63 & $\mathrm{~F}$ & 55 \\
\hline Anita & 26 & $\mathrm{~F}$ & 67 & Deborah & 64 & $\mathrm{~F}$ & 44 \\
\hline Jenny & 26 & $\mathrm{~F}$ & 57 & Katrine & 65 & $\mathrm{~F}$ & 35 \\
\hline Gianpaolo & 27 & M & 74 & Ivan & 67 & M & 66 \\
\hline Mario & 27 & M & 45 & Nick & 68 & M & 48 \\
\hline Marta & 28 & $\mathrm{~F}$ & 53 & Stevie & 69 & M & 84 \\
\hline Mary & 28 & $\mathrm{~F}$ & 53 & Allison & 69 & $\mathrm{~F}$ & 50 \\
\hline Antonio & 28 & M & 62 & Eddie & 70 & $\mathrm{~F}$ & 19 \\
\hline Janet & 28 & $\mathrm{~F}$ & 66 & Mary & 70 & $\mathrm{~F}$ & 12 \\
\hline Gabriele & 29 & M & 60 & Sally & 70 & $\mathrm{~F}$ & 23 \\
\hline Nastaran & 30 & F & 92 & Whitney & 71 & $\mathrm{~F}$ & 64 \\
\hline Bobby & 30 & M & 60 & Stella & 71 & $\mathrm{~F}$ & 57 \\
\hline Chul & 32 & M & 66 & Sasha & 71 & $\mathrm{~F}$ & 56 \\
\hline Janet & 32 & $\mathrm{~F}$ & 74 & Susan & 72 & $\mathrm{~F}$ & 35 \\
\hline Alexandra & 34 & F & 71 & Billy & 72 & M & 61 \\
\hline
\end{tabular}

Note: The participants' names are fictitious. 
Table 5 List of participants of the study (continued)

\begin{tabular}{|c|c|c|c|c|c|c|c|}
\hline \multicolumn{4}{|c|}{ Under 60-year-old participants } & \multicolumn{4}{|c|}{ Over-60-year-old participants } \\
\hline $\begin{array}{l}\text { Fictional } \\
\text { name }\end{array}$ & Age & Gender & TF score & $\begin{array}{c}\text { Fictional } \\
\text { name }\end{array}$ & Age & Gender & TF score \\
\hline Paola & 36 & $\mathrm{~F}$ & 75 & Dany & 73 & $\mathrm{~F}$ & 70 \\
\hline Stijn & 39 & M & 48 & Abigail & 73 & $\mathrm{~F}$ & 46 \\
\hline Paul & 40 & M & 50 & Franky & 74 & M & 18 \\
\hline Margaret & 42 & $\mathrm{~F}$ & 44 & Rachel & 75 & M & 24 \\
\hline Estrella & 44 & $\mathrm{~F}$ & 71 & Justin & 75 & M & 51 \\
\hline Francesco & 45 & M & 75 & Jessica & 76 & $\mathrm{~F}$ & 12 \\
\hline Matthew & 50 & M & 76 & Elizabeth & 76 & $\mathrm{~F}$ & 36 \\
\hline Lyly & 25 & $\mathrm{~F}$ & 60 & Rachel & 77 & $\mathrm{~F}$ & 10 \\
\hline Camilla & 53 & $\mathrm{~F}$ & 49 & Audrey & 77 & $\mathrm{~F}$ & 21 \\
\hline Betty & 56 & $\mathrm{~F}$ & 39 & Jerry & 77 & M & 19 \\
\hline Tony & 58 & M & 61 & Natalie & 83 & $\mathrm{~F}$ & 29 \\
\hline Victoria & 58 & $\mathrm{~F}$ & 70 & Janine & 84 & $\mathrm{~F}$ & 8 \\
\hline Mark & 59 & $\mathrm{~F}$ & 49 & Maggie & 84 & $\mathrm{~F}$ & 0 \\
\hline
\end{tabular}

Note: The participants' names are fictitious.

\section{Data analysis}

Data from the TF questionnaire were analysed with a Spearman's correlation, measuring strength and direction of the association between two ranked variables. The variables to be associated are the age of the 62 participants (independent variable) and their TF score (dependent variable). The sign of the Spearman's correlation indicates the direction of the association between the variable $\mathrm{X}$ (the independent variable) and the variable $\mathrm{Y}$ (the dependent variable).

Data from the smart radio evaluation questionnaire was primarily analysed with a Mann-Whitney $U$ test, a non-parametric statistical test conducted to understand the difference between the distributions of data collected from two subgroups. In the study, the test verifies whether age differences in the two samples had a statistical influence on the answers recorded for each SMs family.

Furthermore, data were analysed seeking convergence and variation in the interpretation of the smart radio between the two subgroups through a frequency analysis of 'matches' between the answers collected and the 'designer mental model of the smart radio', the list of 32 signifiers/signified that the researcher considered as the best pairs and used for benchmark purposes. The aim of such analysis was not the identification of 'right' or 'wrong' answers, but rather a consistency among the interpretation given by subgroups. The frequency analysis was conducted by comparing the percentage of the participants matching the 'design mental model of the smart radio' 
with those who matched each signal with a different signified, defined as 'scattered answers', and those who did not find in the proposed signified options any valid interpretation, defined as 'other' answers. Each percentage was calculated by multiplying the sum of the recorded answers in each sub-group ('matches', 'scattered' and 'other' answers for both analogical and metaphorical messages) for 100, and dividing the resulting value for the maximum amount of answers potentially given by each group of participants in each SMs family. The following formula was adopted:

$$
\% \text { value }=\frac{[(\text { number of recorded answers in each sub group }) * 100]}{\text { maximum number of answers for each SMs family }}
$$

The maximum score achievable for each SMs family was calculated by multiplying the number of participants for the maximum number of matches achievable in each SMs family. Both age groups count 31 participants, meaning that they could potentially match $31 \times 8$ answers with a total of 248 achievable matches in each family of SMs.

In order to further understand how differences in age affect the intuitiveness of each signal of the smart radio, participants were asked to 'score' their signal/meaning preferences, on a scale from 1 to 3, where 1 is 'not intuitive, and 3 is 'very intuitive'. Only the answers that 'matched' the 'designer mental model of the smart radio' were counted and analysed.

Data are further qualitatively explained and justified through feedback gathered from the three open questions at the end of the smart radio evaluation questionnaire.

\section{Findings}

The study sought out the opportunity to convey physically embodied analogies and metaphors to retrieve users' prior knowledge and memories and, ultimately, facilitate the understanding of novel technological products.

The research first addressed whether there was a difference in TF among the younger and older participants' subgroups. The application of the Spearman's rho test in this study confirmed the inverse correlation age/TF also within the context of radio related technologies. In line with the literature (Blackler et al., 2010), there is a negative correlation with statistical significance $(r=-0.610, p=0.0)$ between age and TF.

Moreover, all participants were asked to identify the meanings of all signifiers and these were matched to the 'designer mental model of the smart radio'. The Mann-Whitney $U$ test was applied to define whether the distribution of matches was different in the two subgroups; in other words, whether age influenced the way the device was designed to work. The test revealed that the null hypothesis $(p=0.05)$ could not be rejected, therefore, there is no evidence to support a statistical difference between the recognition of the association's signifier/signified among the two subgroups. In details, the results are shown in Table 6. This finding suggests that the inverse correlation between age and familiarity with technology seemed irrelevant when participants were asked to interact with the smart radio. 
Table 6 Results of the Mann-Whitney U test

\begin{tabular}{lcccccc}
\hline & Matches & Scattered & Others & Matches & Scattered & Others \\
\cline { 2 - 7 } & $\begin{array}{c}\text { Light } \\
\text { emitting } \\
\text { materials }\end{array}$ & $\begin{array}{c}\text { Light } \\
\text { emitting } \\
\text { materials }\end{array}$ & $\begin{array}{c}\text { Light } \\
\text { emitting } \\
\text { materials }\end{array}$ & $\begin{array}{c}\text { Changing } \\
\text { shape }\end{array}$ & $\begin{array}{c}\text { Changing } \\
\text { materials }\end{array}$ & $\begin{array}{c}\text { Changing } \\
\text { materials }\end{array}$ \\
$\begin{array}{l}\text { shape } \\
\text { materials }\end{array}$ \\
\hline Mann-Whitney U & 436.5 & 375. & 435. & 417.5 & 399. & 476.6 \\
Asymp. sig. (2-tailed) & 0.522 & 0.116 & 0.365 & 0.366 & 0.241 & 0.913 \\
\hline & Matches & Scattered & Others & Matches & Scattered & Others \\
\cline { 2 - 7 } & Rheological & Rheological & Rheological & Changing & Changing & Changing \\
& changing & changing & changing & colour & colour & colour \\
& materials & materials & materials & materials & materials & materials \\
\hline Mann-Whitney U & 480.5 & 454.5 & 465. & 396.0 & 439. & 432.5 \\
Asymp. sig. (2-tailed) & 1.0 & 0.710 & 0.743 & 0.227 & 0.553 & 0.219 \\
\hline
\end{tabular}

Note: a. Grouping Variable: age

Furthermore, the participants' responses were analysed to better understand which SMs signals were understood or misinterpreted.

The participants' responses were categorised into three groups:

1 'matches': the participant guessed the designer association of signifier-signified

2 'scattered': the participant associated the signifier to another available signified (function)

3 'other': the participant associated the signifier to a signified not included in the functionality of the smart radio.

Tables $7 \mathrm{a}-7 \mathrm{~b}$ highlight the instances where the sum of 'scattered' and 'other' responses was more than $50 \%$ of the possible responses. This occurred in seven metaphorical messages for the under-60-year-olds and five metaphorical messages for the over-60-years-olds (highlighted in bold). Interestingly, all the five misinterpreted messages reported by the over-60-year-old group are metaphorical and they are the same of those counted in the under-60-year-old group. This insight suggests that both age groups were unable to resolve a cognitive conflict (Duit, 1991) when interpreting these subsets of metaphorical messages, hence the mapping between old and new knowledge domains was ineffective. To be successful a metaphor requires the understanding of the implicit correlation between the domains that it tries to relate, however, the analysis reveals that these less understood metaphorical messages were unable to bridge the two domains. Difficulties in restructuring a new pattern of meanings when exposed to metaphorical messages occurred for several reasons. With regards to changing shape materials, Marta (female, 28) and Mario (male, 27) considered unclear the associations M.15 and M.16 because "don't really characterise any existing object and they appear less intuitive" (Marta). For these participants metaphors failed to be understood because a well-known domain was not easily retrieved; for instance, Mario considered these signals as "too chaotic to be understood", due to the unfamiliar pattern of the moving shapes. 
Participants recognised a mismatch signifier/signified but they were not helped in solving it; therefore, they demanded for a representation of the transition between the two statuses through 'time-related' parameters (LyLy - F, 28 and Mary - F, 28). In their opinion, each signal (signifier) would be easily linked to the expected meaning (signified) by modulating the frequency and the speed of movement of the changing pattern that will eventually solve the mismatch between domains and provide descriptive clues of the human statuses to be represented. Chul $(\mathrm{M}, 32)$ explained how he was not helped in recollecting any human status through the four metaphorical messages; his understanding of the metaphors stuck at the mismatch level with little chances to infer new similarities between the two domains. Therefore, he argued that a programmed modulation of the 'speed of changing shape' would have facilitated the association of each message to the desired human status: "a flap curling - uncurling at certain speed could resemble a human activity of reaching out". Through this lens, the 'time-related' parameters are intrinsic representations of the human statuses that are expected to be represented and would facilitate the metaphorical mapping between domains. More exposure to messages is also a way to acquire more domains' attributes to be matched. Marta demanded for a 'loop' in the changing shape dynamic of metaphorical messages to create a 'flow' of information that would give enough time to retrieve similar information between domains.

The lack of sufficient sensorial stimuli was also considered a further reason for the misinterpretation of metaphorical messages. Alexandra (F, 34) said that 'crinkling shapes' (changing shape materials) can also be combined with lights: "if I do not understand the first one (signifier), I will probably understand the second". In other words, participants asked for more than one signifier communicating the same signified: the first one, they are already familiar with, could help them understand a signifier never encountered before. This is considered a way to facilitate the linking of domains of knowledge in a novel way, whilst also supporting the desired 'surprise' effect that metaphors at time generate for a guided reorganisation of novel meaning. Anita (F, 26) appreciated how rheological changing materials combine both visual and haptic features in one interface; however, she suggested an improved mock-up to better let them experience the dynamic interface. Due to safety concerns, signals embodied with rheological changing materials were simulated through a video support representing their dynamic functionality and with static samples simulating their haptic features. Furthermore, the use of the appropriate image schema is a crucial factor when establishing a link between signified/signifier. With regards to rheological changing materials, William (M, 21) suggested that the size of each bubble could explicitly communicate the activity of the user (bigger size $=$ more energetic activity). Alexandra $(F, 34)$ explained that the variation of the colour spectrum of changing colour materials provided redundant information and, therefore, confusion. She stressed how one colour could have been modulated in different shades to resemble a specific human status. For example, only the colour brightness can be tuned to communicate the level of activity of the connected user, Alexandra said: "the brighter the colour, the more active the user is". Mary $(F, 70)$ considered clear the representation of the activity of the user through the colours spectrum: "I imagined clear colours when the body feels relaxed." 
Table 7a Analysis of the participants' response to the smart radio evaluation: light emitting and changing shape materials

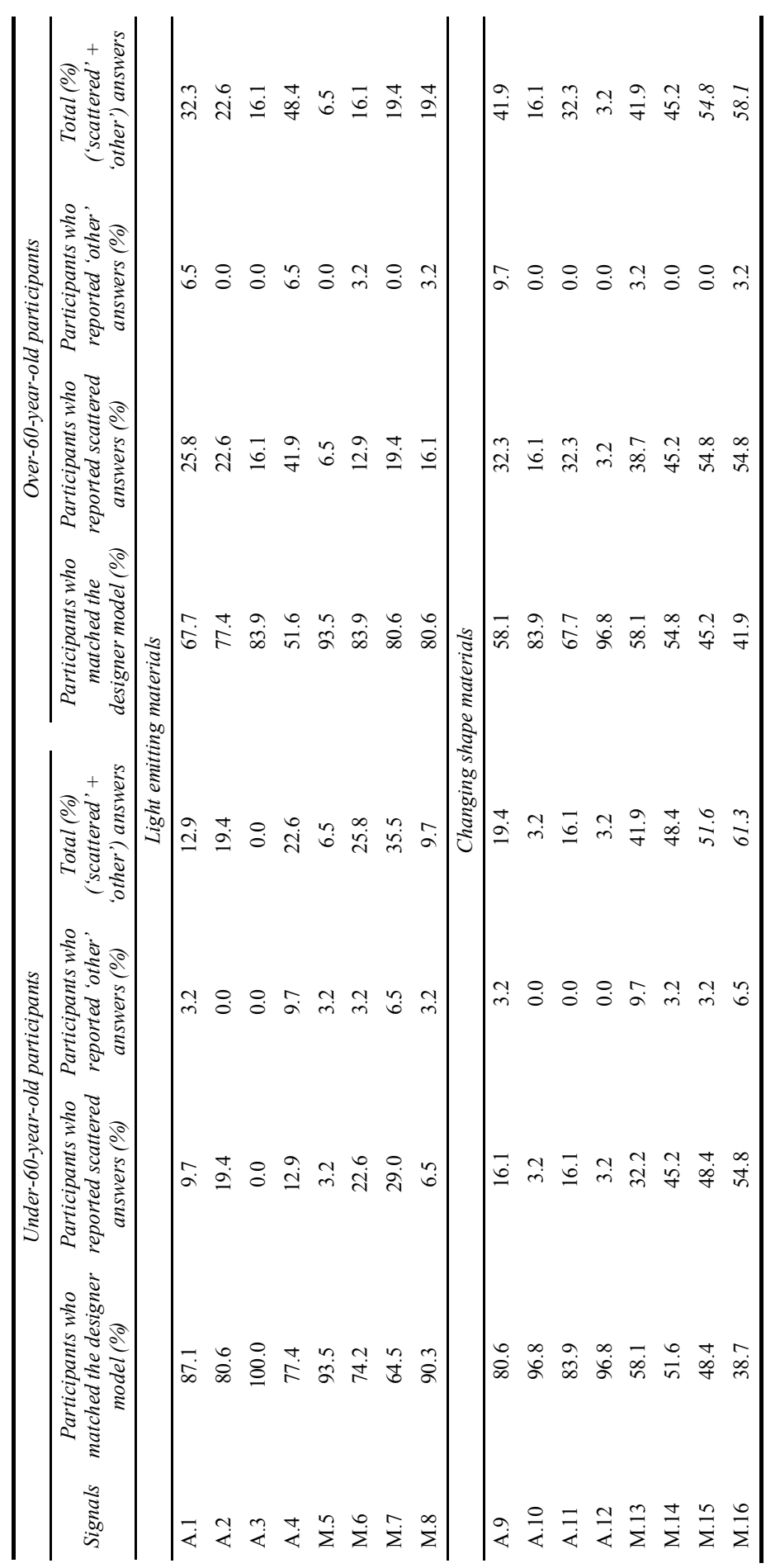


Table 7b Analysis of the participants' response to the smart radio evaluation: rheological changing and changing colour materials

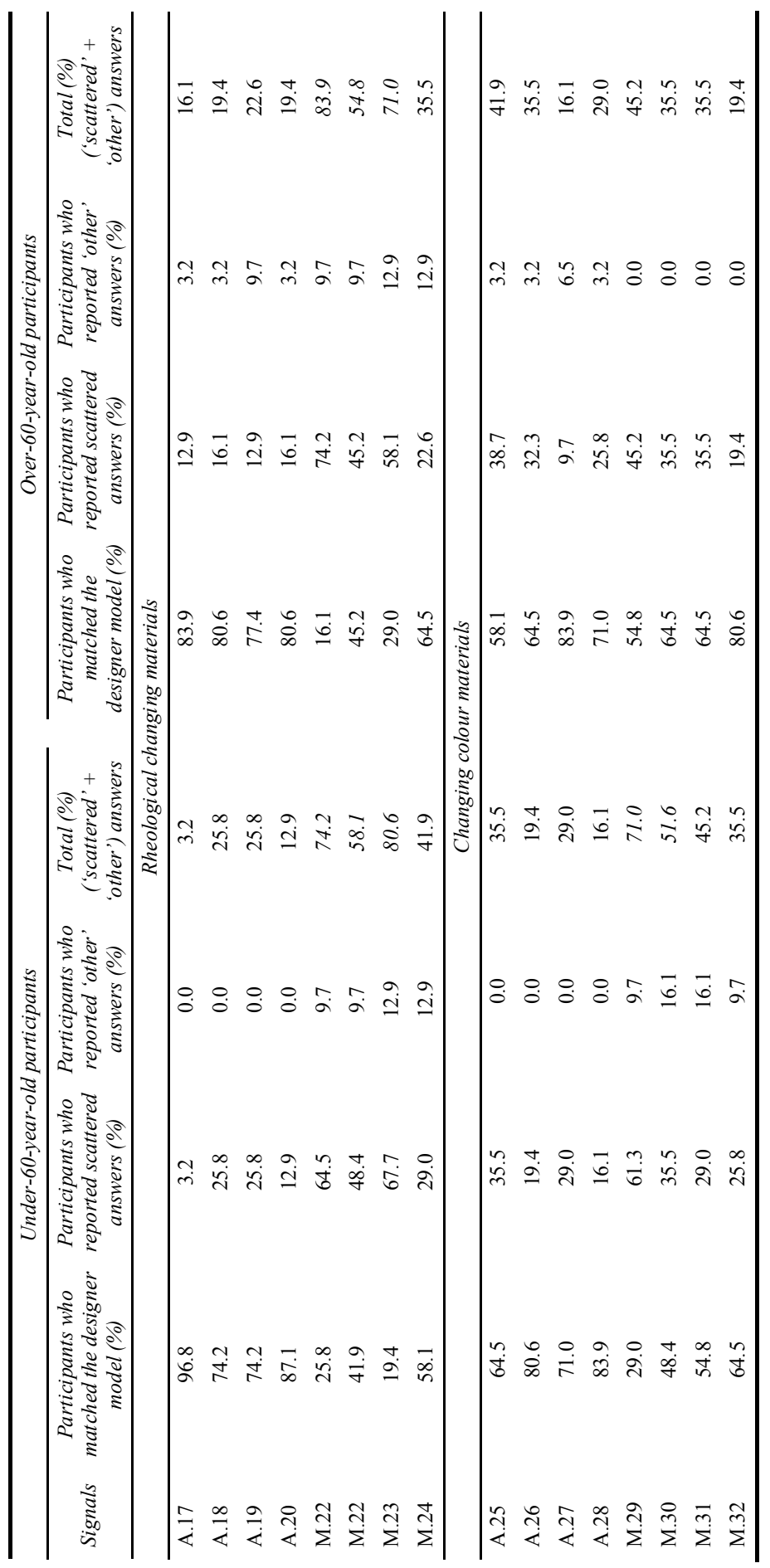


Differences in the interpretation of metaphors suggest that age groups understood each signal with a different degree of intuitiveness, based on the ability of each participant of retrieving one's own stored knowledge, linking it to a novel domain and restructuring knowledge maps. With the intent to understand how age affected the intuitiveness of each signal and which SMs family effectively contributed to reducing age-related differences when understanding the smart radio, participants were asked to 'score' each signifier/signified association, on a scale of 1 to 3 , where 1 is 'not intuitive', and 3 is 'very intuitive'. For this analysis, both 'scattered' and 'other' responses were not considered; the analysis of the distribution of the ratings attributed to each signal/meaning association was conducted to qualitatively understand how the participants intuitively rated each 'match' response. The following graphs display the distributions of the ratings for each SMs family and for the two subgroups respectively.

Figure 5 Intuitiveness score of light emitting materials (see online version for colours)

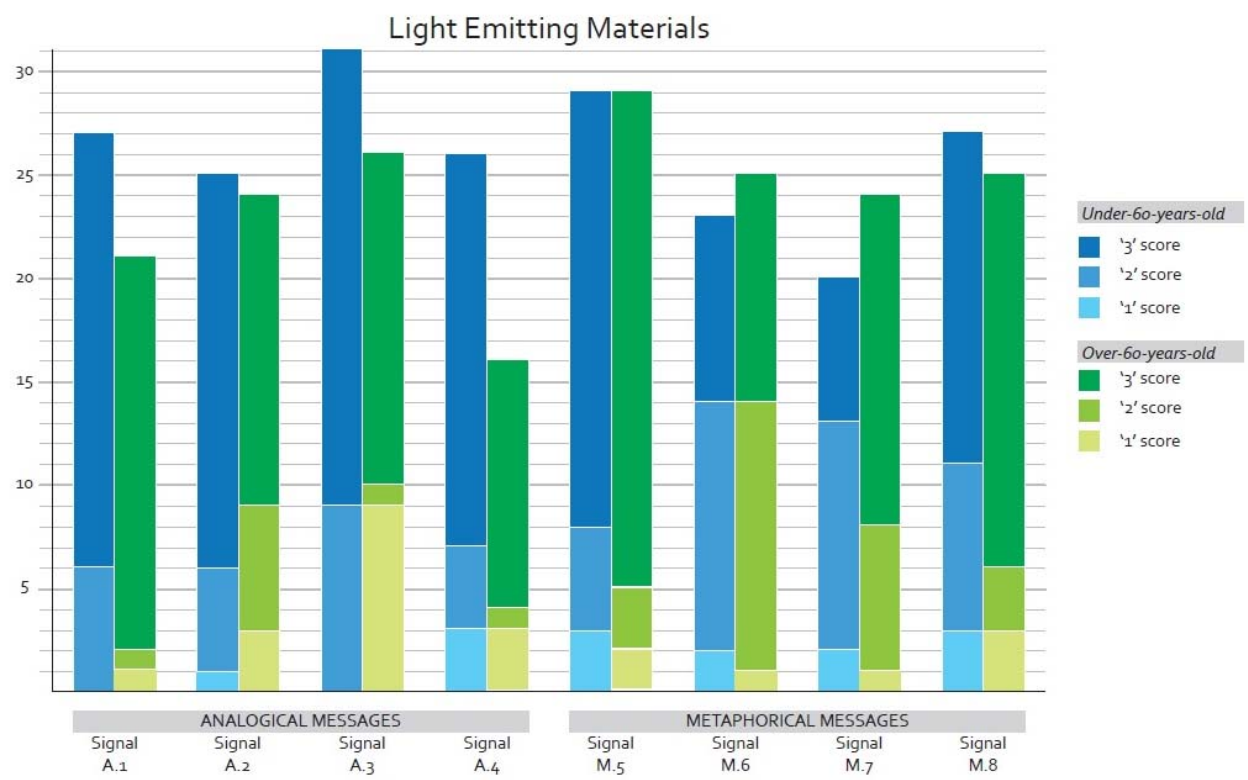

As shown in Figure 5, light emitting materials for the under and over-60-year-old groups were scored as highly intuitive (a total of 132/248 ' 3 ' were collated for the under-60 and a total of 132/248 was given by the over-60). For metaphorical messages, both subgroups considered signal M.6 and M7 as the less intuitive signals among the eight proposed. Lack of understanding for these two signals was caused by: the speed of the emission of the light (active vs. non-active) and the difference between pulsing and blinking (relaxed vs. stimulated) not clearly understood. Gianpaolo (M, 27) noticed that the changing speed and intensity of light recalls the idea of 'danger' that was not considered in the four statuses proposed. This point gives the opportunity to highlight how entrenched mental schemas (fast blinking light $=$ alert) if not appropriately adopted, could affect the intuitiveness of the intended messages. 
Figure 6 Intuitiveness score of changing shape materials (see online version for colours)

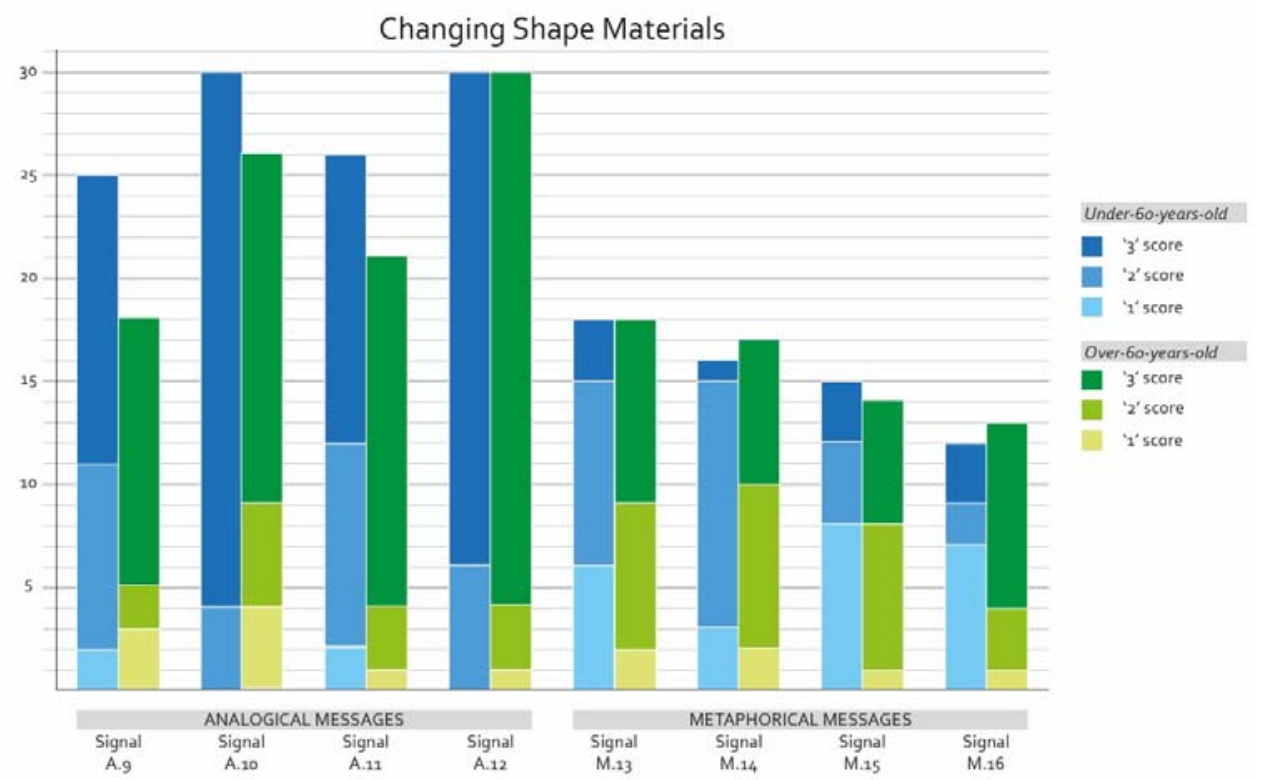

The changing shape materials family displayed a lower score for both age groups (88/248 ' 3 ' were collated for the under-60 and 104/248 was given by the over-60) compared to light emitting materials. Both subgroups reported a more intuitive understanding of analogical messages than metaphorical messages. William, (M, 21) said that: "movable flaps are efficient to convey the message and the meaning of symbols appear reinforced by the movement." The changes in shape helped participants focusing their attention on the messages with smaller chances of error: Antonio (M, 28) confirmed that shape changing materials work better in communicating the availability of the user because: "the immediateness of the movable flaps reduces the possibility of misleading interpretations." Stella (F, 71) appreciated how the moving flaps give a visual contribution to the device while Sasha (F, 71) considers them 'really amusing'. The 'amusement' effect is also important as something that is fun attracts the user attention and, in return, makes one aware of what is going on. Conversely, Figure 6 shows difficulties in the interpretation of metaphorical messages and age does not seem to have an impact on the participants' intuitive interpretation of signals. The most intuitive of these signals is M.13 while the less intuitive is the M.16 for both subgroups. Samantha (F, 24), Johnny (M, 25) and Mary (F, 28) commented on how the changes in shapes (sharp vs. smooth) and the frequency of such changes were not effective to embody different meanings, creating, therefore confusing interpretations.

A total of $63 / 248$ ' 3 ' score was recorded for the under-60s and a total of 89/248 was given by the over-60s for the rheological changing materials. Ratings show an intuitive evaluation of the analogical messages by both age groups that scored with the highest value the signals A.17 and A.20. The unexpected novelty of the interface with rheological changing materials surprised the participants from both age groups. LyLy (F, 28) appreciated the possibility to experience the signals also with the sense of 'touch', and not just with the visual effect of the popping up symbols. Gianpaolo, (M, 27), explained 
how this visual/tangible interaction maximises the effect of a 'changing situation' of the interface. Sharon $(\mathrm{F}, 66)$ described the symbols appearing on the surface as something 'you cannot get wrong'. Justin (M, 79) commented how the tangible symbols activated on the surface of the radio were effective and a possible avenue for visually impaired people.

Figure 7 Intuitiveness score of rheological changing materials (see online version for colours)

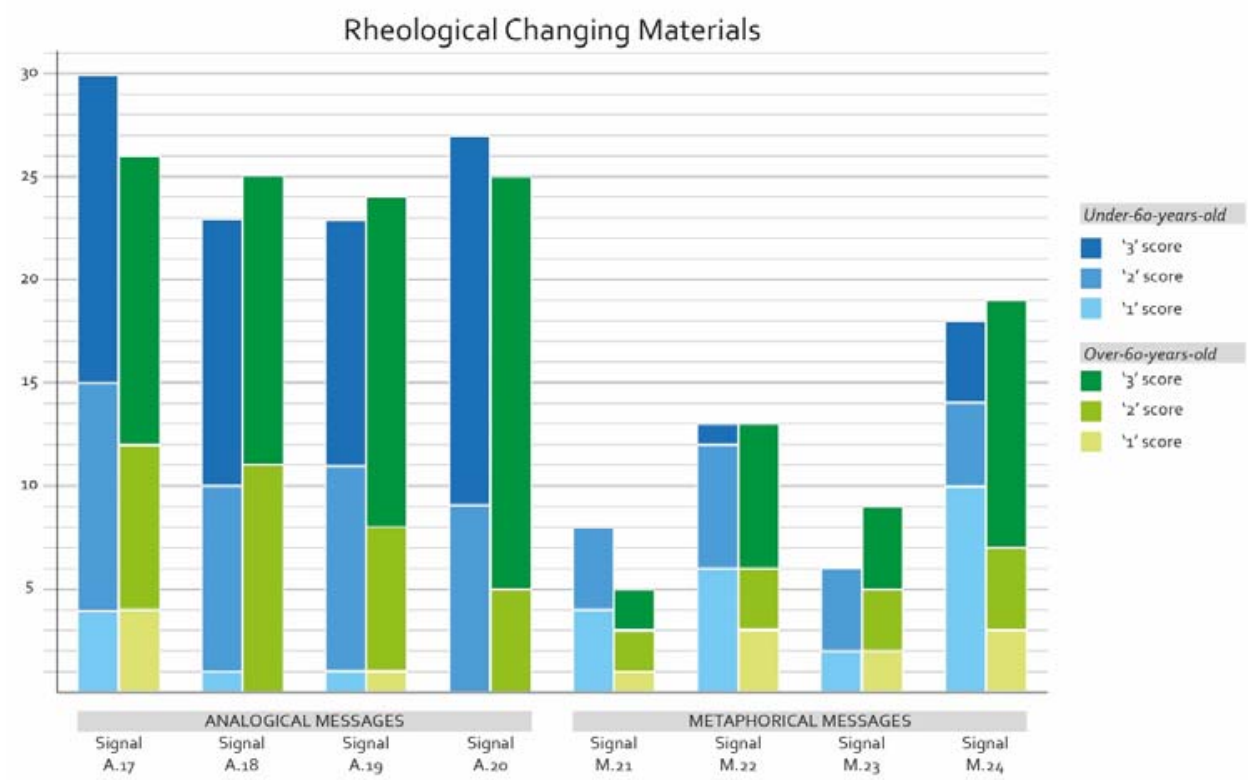

Metaphorical messages in this family were scored as less intuitive than analogical messages for both age groups. The most intuitive signals were those where the physical distance between the popping bubbles was the only variable to be considered (signal M.22 and M.24). The addition of a second variable to be interpreted (the size of each bubble), hindered the interpretation of the remaining messages (M.21 and M.23) confirming how demanding was to retrieve multiple schemas simultaneously. For instance, Nastaran $(F, 30)$ reported how the haptic shapes could not be easily decoded in the way they were designed, and their interpretation was only partially feasible after the four metaphorical messages were compared simultaneously. Participants spontaneously tried to recall a familiar schema on which to build their own reasoning; this process resulted cognitively demanding as it required more than one schema to be recalled, henceforth not immediate.

A total of 78/248 ' 3 ' score was recorded for the under-60s and a total of 116/248 was given by the over-60s to the changing colour materials family. Dissimilarities among the age groups were observed. The highest scores for analogical messages were the A.27 for the over-60s and A.28 for the under-60s. The lowest score was recorded for the signal A.25 in both subgroups. Despite the intuitive interpretation of the analogical messages, Samantha (F, 24) commented that colours have different meanings across cultures, therefore, she considered counter-productive to design an interface that relies exclusively on them while Elizabeth $(F, 76)$ expressed her concern with their effectiveness in 
products for older adults, given that colour perception is severely affected by the ageing process. Deborah $(F, 64)$ claimed how with colours it was easy to fall into a personal interpretation that diverted the attention from the actual meaning of the signals.

Figure 8 Intuitiveness score of changing colour materials (see online version for colours)

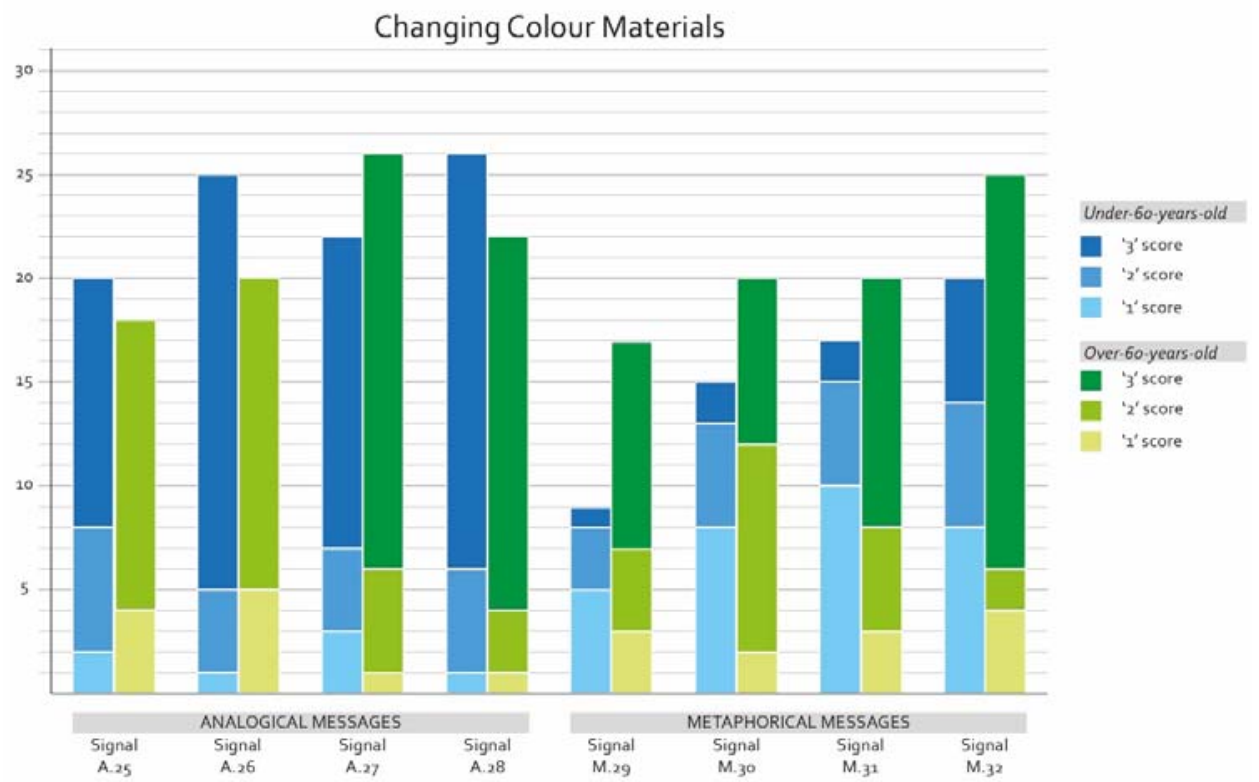

Signals M.29 and M.32 of the metaphorical messages were scored with the lowest and the highest value by both age groups. Participants found the interpretation of the colour spectrums confusing because of their initial attempt to find a defined colour coding, as for the analogical messages ( green $=$ go, red $=$ not go). As commented by Anita $(F, 26)$ signals adopting a variation of the colour spectrum are efficient because: "they can show hard/slow beat of the activity performed as in signals $4.6-4.7$, resulting really powerful". However, she stressed how working with only one colour, in combination with lights and modulated intensity, would reduce the confusion of the interpretation.

\section{Discussion}

Analogical messages helped to create relational structures between old and new target domains for participants in both age groups. The embodiment of the analogical messages was positively considered by participants, who pointed out how each analogical signal was enhanced and 'stood out' emphasising the similarities between linked domains. A reduced comprehension of metaphorical messages compared to analogical messages was observed in all four SMs families. Metaphors are, by definition, relational comparisons of the attributes they match (Gentner, 1983) and not isomorphic correlations between domains; therefore, their understanding presumes the identification and interpretation of parallels between attributes with greater cognitive effort. Although the adoption of embodied SMs was intended as a way to reduce the cognitive effort in the mapping of 
past and new knowledge, in both age groups a lower score in the interpretation of metaphors was expected. The research assumption that SMs could contribute to reducing the comprehension gap among groups with different prior exposure to technologies is supported by the absence of a statistical difference in the answers recorded (Table 6) and the similar trends observed in the intuitiveness of each message (Figures 5-8) regardless of age differences. Moreover, findings suggest that even in the observation of extreme cases (signals less and better understood in each SMs families as Tables $7 \mathrm{a}-7 \mathrm{~b}$ describes) there are significant similarities in the comprehension scores across age groups. Signals equally less understood in the changing shape materials and changing colour materials are the M16 and M29 in both age groups; similarities are also observed in signals better understood within the changing shape materials and rheological changing materials by the two age groups, respectively A12 and A17.

The embodiment of SMs to convey metaphorical messages seems to have flatten the difference in expected scores that the difference in TF would have deemed reasonable to predict, leading to results that are not significantly different among the two age groups; however, the full potential of embodied SMs is yet to be explored. Nevertheless, two important considerations emerge from the study in support of the design of embodied SMs and are described in what follows.

\subsection{Composite metaphors with a dominant attribute}

Misalignments between domains are normal in a metaphorical learning process; however, when a single metaphor has insufficient attributes to help people to infer new knowledge, a 'composition' of metaphors supports a complete representation of the target system (Neale and Carroll, 1997; Marcus, 1994). As participants suggested, the combination of lighting signals with touch and/or colour coding is a way to strengthen the representation of the target domain. In addition, this 'composition' effect seemed not to have any extra cognitive cost as some elements of the mapping required to understand the metaphor (dominant attribute) had already occurred and the new knowledge links on the established mapping. Data suggest how to leverage dominant SMs families to embodied metaphorical messages: light emitting materials for both age groups and changing colour materials for the over-60 subgroup were the two families better understood and, therefore, those on which composite metaphors should be built upon. The 'composite' effect aforementioned seems to be different from the 'systematicity' principle highlighted by Gentner and Colhoun (2010) assuming that the individual seeks to align interconnected systems of relations in the source and target domains as this has more powerful predictive power than an equal number individual elements matched. What was observed and proposed as 'composite' effect is a learning process by which the use of a product is facilitated when the individual collate pieces of inference that per se would not be strong enough to make prediction, but that, together, reinforce each other, clarify the matches and eventually make for stronger matches. This is an important insight for product design as the user, and the designer, have several sensorial channels to simultaneously suggest the matches and their composite effect may not only facilitate the understanding and use of the product, but also cater for diverse learning styles. 


\subsection{Narrative-based metaphors}

In the comprehension of metaphors, participants introduced the 'time' element with the intent to maximise the SMs' properties toward a successful alignment between domains. Specifically, participants asked for more exposure to rheological changing and changing shape materials. A 'loop' in the signal's display was demanded to have more time with signals and increase the possibility to directly touch and interact with them. A 'direct manipulation' with the signals was considered a way to enhance the connection between the action of the user and the language of the interface, by providing further details to encode metaphors and reduce mismatches between domains (Neale and Carroll, 1997). In other words, the longer the user is exposed to metaphors the more likely he can link two domains. Furthermore, the subset of the four metaphorical messages of changing shape materials was designed upon image schemas (big/small crinkling, up/down movement and curl up enablement) that required additional time to be interpreted. Retrieving three schemas simultaneously was considered demanding and confusing, while participants were looking for one dominant schema activation as a key of interpretation (see Section 5.1 for the 'composite' effect). In this view, 'time' could be considered itself a metaphor's attribute: the speed of shapes' changing may recall emotions and stored knowledge entrenched in the human experienced and, therefore, be used to intuitively link with a novel domain. Moreover 'time' was also perceived as an opportunity to display a 'story' on the device interface making embodied SMs vehicles of 'narrative' especially for changing shape materials and changing colour materials. Narrative, defined as a sequence of events, mental states, and behaviours whose meaning is given by the configuration of the sequence as a whole (Bruner, 1990), links these elements in a logical relationship and allows the receiver to engage in a meaningful construction process; therefore, narrative helps to make sense of experience and supports learning with regard to cognition, motivation and emotions (Dettori and Paiva, 2009). Embodied metaphors maximise the cognitive links between shared domains attributes making them evolve and change in a flow of narration that supports the receiver's engagement. Dettori and Pavia (ibid.) highlight that narrative can support the receiver also at an emotional level, stimulating curiosity and fantasy, which are important components of learning. When metaphors are able to combine entrenched knowledge and participants' feelings in the conveyance of a message, metaphors can be powerful and less cognitively demanding. This is the foundation of narrative-based metaphors that the 'time' dimension, an additional property of the metaphor, can enrich. This may eventually help users discriminating among similar shared attributes, as required by age-related changes in cognition (Elfman et al., 2008).

\section{Conclusions}

This paper paves the way to explore the use of analogical learning in product design through the application of SMs. This is with the intent to facilitate the adoption of technological products among the older adults who may benefit from recalling entrenched knowledge through the use of analogies and metaphors embodied in the product interface. 
The study of analogical learning, from literal similarities, to analogies and to metaphors, are extensive in cognitive sciences and psychology, however, there are few exploitations of such literature to improve the design of technology so that the digital divide still experienced by the ageing population could be bridged. Whilst this is just an initial step in understanding the cross-dimensional application of analogies and metaphors, from conceptual tools to interface strategy, the research has revealed that maximising sensorial stimuli through SMS-based interfaces could be a potentially successful strategy to improve technology adoption among late adopters.

The adoption of SMs in a non-linguistic metaphors context has demonstrated that the application of embodied SMs may significantly facilitate older adults in linking past and new knowledge with the intent to intuitively interact with products they had limited prior exposure to. This study also suggests that multiple signs conveying the same signifier may be helpful in reducing products' ambiguity in what we described as the composite effect. Adding 'time' as a property of the metaphor allows for a further interpretation of the same as it recreates narrative structures that people, regardless of age, recognise.

\section{Acknowledgements}

This research study has been partially supported by the EU-funded FP7 collaborative research project Light.Touch.Matters (LTM), under agreement no. 310311. The authors further want to thank all the participants who took part in the study.

\section{References}

Bakker, S., Antle, A.N. and Van Den Hoven, E. (2012) 'Embodied metaphors in tangible interaction design', Personal and Ubiquitous Computing, Vol. 16, No. 4, pp.433-449.

Barnard, Y., Bradley, M.D., Hodgson, F. and Lloyd, A.D. (2013) 'Learning to use new technologies by older adults: perceived difficulties, experimentation behaviour and usability', Computers in Human Behavior, Vol. 29, No. 4, pp.1715-1724.

Beer, S. (1966) Decision and control: the meaning of operational research and management cybernetics, p.556, Wiley, London.

Blackler, A., Popovic, V. and Mahar, D. (2010) 'Investigating users' intuitive interaction with complex artefacts', Applied ergonomics, Vol. 41, No. 1, pp.72-92.

Blackler, A.L. and Hurtienne, J. (2007) 'Towards a unified view of intuitive interaction: definitions, models and tools across the world', MMI-Interaktiv, Vol. 13, No. 2007, pp.36-54.

Blackler, A.L., Popovic, V., Mahar, D.P., Reddy, R. and Lawry, S. (2012) 'Intuitive interaction and older people', in Proceedings of the Design Research Society (DRS) 2012 Conference, Department of Industrial Design, Faculty of Architecture, Chulalongkorn University, pp.560-578.

Bruner, J.S. (1990) Acts of Meaning, Vol. 3, Harvard University Press, Cambridge, Massachusetts London, England.

Cila, N. (2013) Metaphors we Design by: the Use of Metaphors in Product Design, Doctoral dissertation, Tu Delft, Delft University of Technology.

Czaja, S.J., Charness, N., Fisk, A.D., Hertzog, C., Nair, S.N., Rogers, W. A. and Sharit, J. (2006) 'Factors predicting the use of technology: findings from the center for research and education on aging and technology enhancement (CREATE)', Psychology and Aging, Vol. 21, No. 2, p.333. 
Dettori, G. and Paiva, A. (2009) 'Narrative learning in technology-enhanced environments', in Technology-Enhanced Learning, pp.55-69, Springer, Dordrecht.

Digital Inclusion Panel (2004) Enabling a Digitally United Kingdom, A framework for Action [online] http://www.umic.pt/images/stories/publicacoes/digitalframe.pdf (accessed September 2016).

Duit, R. (1991) 'On the role of analogies and metaphors in learning science', Science Education, Vol. 75, No. 6, pp.649-672.

Elfman, K.W., Parks, C.M. and Yonelinas, A.P. (2008) 'Testing a neurocomputational model of recollection, familiarity, and source recognition', Journal of Experimental Psychology: Learning, Memory, and Cognition, Vol. 34, No. 4, p.752.

Fisk, A.D., Rogers, W.A., Charness, N., Czaja, S.J. and Sharit, J. (2009) Designing for Older Adults: Principles and Creative Human Factors Approaches, CRC Press, Boca Raton, London; New York.

Fulop, T., Larbi, A., Witkowski, J.M., McElhaney, J., Loeb, M., Mitnitski, A. and Pawelec, G. (2010) 'Aging, frailty and age-related diseases', Biogerontology, Vol. 11, No. 5, pp.547-563.

Gagné, R.M. (1970) The Conditions of Learning, Holt, Rinehart, \& Winston, New York.

Gentner, D. (1983) 'Structure-mapping: a theoretical framework for analogy', Cognitive Science, Vol. 7, No. 2, pp.155-170.

Gentner, D. (1989) ‘Analogical learning', Similarity and Analogical Reasoning, p.199.

Gentner, D. and Colhoun, J. (2010) 'Analogical processes in human thinking and learning', In Towards a Theory of Thinking, pp.35-48, Springer, Berlin, Heidelberg.

Gibbs, R.W. and Colston, H.L. (1995) 'The cognitive psychological reality of image schemas and their transformations', Cognitive Linguistics (Includes Cognitive Linguistic Bibliography), Vol. 6, No. 4, pp.347-378.

Government Office for Science (2015) 'How are attitudes and behaviours to the ageing process changing in light of new media and new technology? How might these continue to evolve by 2025 and 2040?', Future of an Ageing Population: Evidence Review [online] https://www.gov.uk/government/uploads/system/uploads/attachment_data/file/455176/gs-1517-future-ageing-attitudes-new-technology-er08.pdf (accessed September 2016).

Gowin, D.B. (1983) 'Misconceptions, metaphors, and conceptual change: once more with feeling', in Proceedings of the International Seminar on misconceptions in Science and Mathematics, June, Department of Education, Cornell University, Ithaca, NY, pp.39-41.

Grady, J. (1997) Foundations of Meaning: Primary Metaphors and Primary Stress, University of California, Berkeley.

Gregor, P., Newell, A.F. and Zajicek, M. (2002) 'Designing for dynamic diversity: interfaces for older people', in Proceedings of the 5th International ACM Conference on Assistive Technologies, July, pp.151-156, ACM.

Heart, T. and Kalderon, E. (2013) 'Older adults: are they ready to adopt health-related ICT?', International Journal of Medical Informatics, Vol. 82, No. 11, pp.e209-e231.

Hey, J., Linsey, J., Agogino, A.M. and Wood, K.L. (2008) 'Analogies and metaphors in creative design', International Journal of Engineering Education, Vol. 24, No. 2, p.283.

Hill, R., Beynon-Davies, P. and Williams, M.D. (2008) 'Older people and internet engagement: acknowledging social moderators of internet adoption, access and use', Information Technology \& People, Vol. 21, No. 3, pp.244-266.

Hurtienne, J., Klöckner, K., Diefenbach, S., Nass, C. and Maier, A. (2015) 'Designing with image schemas: resolving the tension between innovation, inclusion and intuitive use', Interacting with Computers, Vol. 27, No. 3, pp.235-255.

Internet World Stat (2017) http://www.internetworldstats.com/stats.htm (accessed April 2018).

Jensen, B.G. (2008) 'Design solutions for an ageing society', in Design Solutions for an Ageing Society, Cumulus working papers Kyoto 20/08. 
Johnson, M. (2013) The Body in the Mind: The Bodily Basis of Meaning, Imagination, and Reason, University of Chicago Press.

Kortuem, G., Kawsar, F., Sundramoorthy, V. and Fitton, D. (2010) 'Smart objects as building blocks for the internet of things', IEEE Internet Computing, Vol. 14, No. 1, pp.44-51.

Krippendorff, K. and Butter, R. (2008) 'Semantics: meanings and contexts of artifacts', in Schifferstein, H.N.J. and Hekkert, P. (Eds.): Product Experience, pp.353-376, Elsevier, New York, NY.

Lakoff, G. and Johnson, M. (2008) Metaphors We Live By, University of Chicago Press, Chicago.

Lee, C. and Coughlin, J.F. (2015) 'Perspective: older adults' adoption of technology: an integrated approach to identifying determinants and barriers', Journal of Product Innovation Management, Vol. 32, No. 5, pp.747-759.

Leonardi, C., Albertini, A., Pianesi, F. and Zancaro, M. (2010) 'An exploratory study of a touch-based gestural interface for elderly', in Proceedings of the 6th Nordic Conference of Human-Computer Interaction: Extended Boundaries, October, pp.845-850, ACM.

Lozada, J., Roselier, S., Periquet, F., Boutillon, X. and Hafez, M. (2010) Magneto Rheological Technology for Human-Machine Interaction, Mechatronic Systems Applications, edited by Milella, A., Di Paola, D. and Cicirelli, G., InTech, ISBN: 978-953-307-040-7 [online] http://www.intechopen.com/books/mechatronic-systems-applications/magneto-rheologicaltechnology-forhuman-machine-interaction.

Marcus, A. (1994) 'Metaphor mayhem: mismanaging expectation and surprise', Interactions, Vol. 1, No. 1, pp.41-43.

Melenhorst, A.S., Rogers, W.A. and Bouwhuis, D.G. (2006) 'Older adults' motivated choice for technological innovation: evidence for benefit-driven selectivity', Psychology and Aging, Vol. 21, No. 1, p.190.

Micocci, M., Spinelli, G. and Ajovalasit, M. (2017) 'Actualizing agency through smart products: smart materials and metaphors in support of the ageing population', in Proceedings of the 6th STS Italia Conference - Sociotechnical Environments, pp.24-26.

Mitzner, T.L., Boron, J.B., Fausset, C.B., Adams, A.E., Charness, N., Czaja, S.J. and Sharit, J. (2010) 'Older adults talk technology: technology usage and attitudes', Computers in Human Behavior, Vol. 26, No. 6, pp.1710-1721.

Mohs, C., Hurtienne, J., Israel, J.H., Nau-mann, A., Kindsmüller, M.C., Meyer, H.A. and Pohlmeyer, A. (2006) 'IUUI - Intuitive use of user interfaces', in. Bosenick, T., Hassen-zahl, M., Müller-Prove, M. and Peissner, M. (Hrsg.): Usability Professionals 06, Stuttgart: German Chapter der Usability Pro-fessionals' Association, pp.130-133.

Morris, A., Goodman, J. and Brading, H. (2007) 'Internet use and non-use: views of older users', Universal Access in the Information Society, Vol. 6, No. 1, pp.43-57.

Naumann, A.B., Wechsung, I. and Hurtienne, J. (2010) 'Multimodal interaction: a suitable strategy for including older users?', Interacting with Computers, Vol. 22, No. 6, pp.465-474.

Neale, D.C. and Carroll, J.M. (1997) 'The role of metaphors in user interface design', in Helander, M., Landauer, T.K. and Prabhu, P. (Eds.): Handbook of Human-Computer Interaction, 2nd ed., Chapter: 20, pp.441-462, Elsevier, North Holland.

Nijholt, A., Giusti, L., Minuto, A. and Marti, P. (2012) 'Smart material interfaces: a material step to the future', in Proceedings of the 1st Workshop on Smart Material Interfaces: A Material Step to the Future, October, p.1, ACM.

Office for National Statistics (ONS) (2017) https://www.ons.gov.uk/businessindustryandtrade/ itandinternetindustry/datasets/internetusers (accessed April 2018).

Özcan, E. and Sonneveld, M. (2009) 'Embodied explorations of sound and touch in conceptual design', DeSForM, Vol. 9, pp.173-181.

Papaefthimiou, S. (2010) 'Chromogenic technologies: towards the realization of smart electrochromic glazing for energy-saving applications in buildings', Advances in Building Energy Research, Vol. 4, No. 1, pp.77-126. 
Ritter, A. (2007) Smart Materials in Architecture, Interior Architecture and Design, Walter de Gruyter.

Rogers, W.A., Meyer, B., Walker, N. and Fisk, A.D. (1998) 'Functional limitations to daily living tasks in the aged: a focus group analysis', Human Factors, Vol. 40, No. 1, pp.111-125.

Saffer, D. (2005) 'The role of metaphor in interaction design', Information Architecture Summit, p.6.

Spinelli, G., Micocci, M. and Ajovalasit, M. (2017) 'Older adults' behavioural strategies in the adoption of new technology-based products: the effects of ageing and the promising application of smart materials for the design of Smart products', Design for Health, pp.358-374, Routledge, London and New York.

Tsoukas, H. (1991) 'The missing link: a transformational view of metaphors in organizational science', Academy of Management Review, Vol. 16, No. 3, pp.566-585. 